\title{
Survey on the Relationship between the Number of Medical Technologists and the Medical Test Count
}

\author{
${ }^{1}$ Department of Biomedical Laboratory Science, Kyungbok University, Porcheon, Korea \\ ${ }^{2}$ Department of Biomedical Laboratory Science, Kyungdong University, Wonju, Korea \\ ${ }^{3}$ Hyun Jinhae Internal Medicine Clinic, Seoul, Korea \\ ${ }^{4}$ Department of Laboratory Medicine, Asan Medical Center, Seoul, Korea
}

Junghyun Kim ${ }^{1}$, Dae-Eun Kim ${ }^{1}$, Joong-Soo Yoon ${ }^{2}$, Jeong Soo Lee ${ }^{3}$, Tae-Wha Park ${ }^{4}$

\section{검사건수에 따른 임상병리사의 인원편성에 관한 설문조사 분석}

\author{
김정현 ${ }^{1}$, 김대은 ${ }^{1}$, 윤중수 $^{2}$, 이정수 ${ }^{3}$, 박태화 ${ }^{4}$ \\ ${ }^{1}$ 경복대학교 임상병리학과, ${ }^{2}$ 경동대학교 임상병리학과, ${ }^{3}$ 현진해내과의원, ${ }^{4}$ 서울아산병원 진단검사의학과
}

\begin{abstract}
This study examined the relationship between the number of medical technologists and the medical test count. Data was obtained from 441 medical technologists in a hospital through a self-reported questionnaire. The Pearson correlation test, student's t-test, ANOVA or descriptive statistics were performed for data analysis. The distribution of medical technologist according to the size of hospitals was small 5.8, medium 14.9, large 25.8, and super 45.4. The analysis demonstrated a relationship between the number of medical technologists and the number of medical tests in the field, number of clinical tests per MT, and number of optimal medical test per MT according to the hospital size $(P<0.001)$. The average time for quality control by the department at a higher hospital was less than two hours. In terms of the satisfaction of salary, work environment, test accomplishment, and welfare service, the dissatisfaction of medical technologists in small and medium hospitals was higher than those in large and super hospitals. Overall, a focus on intensifying systemic supplementation and improving the condition of medical technologists is needed to provide reliable data for medical examinations in medical areas.
\end{abstract}

Key words: Biomedical laboratory science, Medical technologist, Medical test, Work force

This is an Open Access article distributed under the terms of the Creative Commons Attribution Non-Commercial License (http://creativecommons.org/licenses/by-nc/4.0) which permits unrestricted non-commercial use, distribution, and reproduction in any medium, provided the original work is properly cited.

Copyright @ 2019 The Korean Society for Clinical Laboratory Science. All rights reserved.
Corresponding author: Joong-Soo Yoon Department of Biomedical Laboratory Science, Kyungdong University, 815 Gyeonhwon-ro, Wonju 26495, Korea Tel: 82-33-738-1371 Fax: 82-33-738-1279 E-mail: yjs101025@kduniv.ac.kr ORCID: https://orcid.org/0000-0003-1717-4720

Received: January 2, 2019

Revised: February 11, 2019

Accepted: February 19, 2019

\section{서 론}

의료환경은 여러 방면의 다각적 변화를 보이고 있으며 국민 들의 의료서비스 대한 다양한 요구가 증대되고 있다. 보건의료 인력 수요는 인구집단의 의료서비스 수요와 보건의료 인력의 생산성을 고려하여 결정된다[1]. 국민소득과 교육수준 및 생활 수준의 향상과 의학의 발달로 평균수명의 연장 및 건강에 대한 관심 증대는 전반적으로 보건의료에 대한 수요로 증가되고 있 다[2-4]. 이러한 다양한 의료서비스 요구의 변화로 인해 다양한
방법의 진단 및 치료의 필요 및 행해짐으로써 이를 수행할 수 있 는 전문 보건의료 인력의 적정 서비스의 공급과 확보는 중요한 요소이다[5]. 현대사회에는 인구경제사회구조의 변화에 따른 의료수요의 다양화 및 의료분야의 첨단과학화 - 세분화가 빠르 게 진행되고 있는바, 이에 따른 의료 인력을 효율적으로 계획하 고 관리하는 것이 필요하다[6-10].

최근의 임상병리사의 역할은 근본적인 변화를 겪었으며, 검 사 분석의 정확성을 높이고 엄격한 테스트 선택 및 결과 해석이 필요로 요구되고 있다. 임상병리사들은 실시간 진단검사의 결 
과 보고 및 검사의 효과, 임상 컨설팅의 역할, 치료의 결정 참여, 질병의 예방 노력, 케어에서 증거 기반 의학으로의 역할과 의무 에 기여하고 있다. 또한 McGaghie는 의료서비스 질의 향상, 임 상 결과 향상, 공동 임상 및 진단검사의학의 연구 프로젝트 수행 변화를 일으키는 주요 요인으로의 임상병리사의 새로운 역할은 그에 따른 필요한 지식과 기술의 중요성에 대한 인식이라고 강 조하였다[11]. 고품질 건강관리에 대한 의료 진단검사의학의 역할과 기여의 변화를 유지하는 중요한 요소는 임상병리사의 능력 및 검사 분야의 환경이라 할 수 있다[12]. 진단검사의학과 의 책임자는 임상병리사의 인적자원을 활용하고 배치하며 그 능력을 극대화 할 수 있도록 도와주어야 하며 이를 통해 업무수 행에 적합한 진단검사의학과를 관리하여야 한다. 최근 대부분 의 병원경영의 악화로 경영을 정상화하기 위한 수단으로 인력 부분의 감축을 시행하고 있으며 특히 진단검사의학과, 병리과, 생리기능진단검사의학과 등에 대한 인력구조 개편이 각 병원마 다 경영합리화를 위한 개선으로서 악용되고 있다. 그러나 우리 나라의 경우 열악한 진단검사의학과의 인력 운영을 경험으로 느끼고 있지만 이를 뒷받침할 만한 증거로서 아직까지 전국적 인 규모로 특히 소규모 병원급에서의 임상병리사 운용 실태에 대한 체계적인 자료는 부족하다고 생각된다. 진단검사의학과 의 적정한 인력규모의 활용은 대단히 중요하다. 병원내의 임상 병리사 인력의 과잉은 병원 및 기관의 경영악화를 가져올 수 있 지만 반대로 열악한 인력운용은 모든 검사의 질 저하를 반드시 수반할 수밖에 없기 때문이다. 이를 판단하는 기준을 확립하는 일은 매우 복잡하고 아직 표준화된 지침은 갖춘 나라는 없는 실 정이다. 과거 업무표준량을 기준으로 한 진단검사의학과의 업 무량에 대한 평가가 있기는 했으나 이 역시 인력운용의 형태보 다는 진단검사의학과를 단순히 임상병리사의 업무량의 다소에 따라 판단하여 보조적인 수단으로만 활용할 수는 없을 것 같다. 진단검사의학의 인력의 적정성을 판별하려면 진단검사의학과 의 규모 및 업무의 복잡성을 꼭 염두에 두어야 한다. 진단검사의 학과는 병원이나 특정기관에서 차지하는 특별한 임무와 목적이 있으며 이 조직은 왜 존재하며 언제 어떻게 그 목표를 수행해야 하는가에 대한 이유가 명확해야 한다. 따라서 진단검사의학과 의 모든 구성원은 각자의 역할을 이해하고 그 목표를 성취하기 위하여 기여해야한다. 그리고 이 목표를 성취하기 위해서는 진 단검사의학과의 적정한 인원과 양질의 검사 시약, 그리고 기기 및 소모품 등 제반 사항이 구비되어야 한다. 병원에서의 임상병 리학 검사는 인건비가 차지하는 비중이 높고, 미국의 경우 진단 검사의학과 비용의 $60 \sim 80 \%$ 를 인건비가 차지하고 있는 것으 로 보고되고 있다. 그러나 병원 경영자는 진단검사의학과의 업
무수행에 있어서 적절한 인력을 보유하고 있는가, 임상병리사 의 검사 난이도에 충분한 경력과 풍부한 경험을 가지고 있는가 는 간과하는 경우가 많다. 우리나라에서는 현재 임상병리전문 의가 없는 준·종합병원의 진단검사의학과뿐만 아니라 임상병 리전문의가 운영하고 있는 중대형종합병원의 진단검사의학과 도 각 병원에 따라 인력이 업무의 종류 및 업무량에 따라 적정하 게 분배되어 있는지에 대한 연구가 체계적으로 이루어진 바가 없다. 임상병리사 인력이 급증한 2000년 이후 우리나라 임상병 리사 인력 공급은 양적 팽창을 가져왔고 수요도 급증하고 있으 나 근무현황, 인력추계, 협회 가입을 통한 전문가 활동에 대한 분석은 이루어지지 않았다. 기존연구는 의사, 간호사 및 보건의 료인직종 중심으로 공급 및 현황을 분석하고, 수요를 파악하여 미래의 적정 인력 수급을 추계하는 연구[13-16]와 업무량 분석 $[17,18]$ 이 대부분이다. 이에 본 연구는 그에 대한 기초자료로서 병원별 임상병리사의 인력배치 및 검사건수 현황을 파악하여 향후 임상실무 건수와 인원편성 계획의 단초를 제공하고자 한다.

\section{재료 및 방법}

\section{1. 연구대상 및 자료수집}

본 연구는 국내의 진단검사의학과의 검사현황 및 인력배치 현황과 검사의 종류 및 건수를 알 수 있도록 대한 임상병리사협 회에 가입되어 있는 지역별 규모별로 면허자격제도에 의한 전 문직으로의 면허를 받아 전문 고유직무를 수행하고 있는 임상 병리사를 대상으로 구조화된 설문지를 통한 설문조사를 실시하 였다. 설문문항은 총 37 문항으로 진단검사의학과에 관한 사항 23 문항, 정도 관리 1 문항, 응답자의 일반적 사항 13 문항으로 구 성하였다. 조사기간은 2017년 10월 1일부터 2017년 12월 31 일까지 설문조사를 실시하여 총 500부 중 문항 미응답 및 결측 값 59부를 제외한 최종 441 부를 최종 분석 자료로 사용하였다. 설문문항의 신뢰도 검증을 위한 크론바흐 알파계수(Cronbach's alpha)는 0.812 로 나타나각 측정항목의 내적일관성은 충분한 것으로 판단되었다.

\section{2. 통계분석}

설문지 결과의 데이터 분석은 통계프로그램 STATA (version 12.0: StataCorp, College Station, TX)를 이용하여 각 항목에 대한 기술통계(descriptive statistics analysis), Chi-square test, ANOVA test 실시하였고 빈도(Frequency)와 백분율(\%) 로 표시하였다. 모든 통계적 유의수준은 $P<0.05$ 로 정하였다. 


\section{결 과}

\section{1. 일반적 특성}

분석대상의 임상병리사의 성별은 여성 $72.3 \%$, 남성 $27.4 \%$ 이고 연령은 30 대 $43 \%, 20$ 대 $28 \%, 40$ 대 $26 \%$ 였다. 결혼 여부는 미혼 $45.8 \%$, 기혼 $54.0 \%$ 로 나타났다. 임상병리사의 업무관련 최종학력은 전문학사 $41.7 \%$, 대졸 $49.4 \%$, 석사이상 $8.9 \%$, 기타 $0.9 \%$ 로 연구 대상자의 대부분이 전문학사졸 이상이었다. 임상 병리사의 재직기간은 1 4년 44.2\%, 5 9년 23.6\%, 10 19년 $11.6 \%, 20$ 년 이상 $26.6 \%$ 로 5년 이상의 경력자가 전체의 $56 \%$ 로 진단검사의학과의 대부분이 경력자를 중심으로 운영되고 있었 다. 고용형태는 정규직이 $88 \%$ 이었으며, 연봉수준은 2,000 3,000 만원 41.5\%, 3,000 4,000만원 21.3\%, 4,000만원이상 $27.7 \%$ 로 나타났다(Table 1).

\section{2. 만족도}

연봉의 만족도는 보통으로 나타났다. 근무환경만족도, 검사 성취도는 보통 이상의 긍정적인 응답이 많았으며 지원받고 있 는 복지제도는 보수교육비, 연회비 및 면허수당, 학자금, 교통 비, 식비 순으로 나타났다(Table 2).

\section{3. 임상병리사 수}

Table 3은 병원 규모별에 따른 임상병리사의 수와 고용형태 를 나타낸다. 근무하는 임상병리사의 수는 의원급 1 6명 $67.3 \%$, 병원급 1 6명 49.5\%, 7 15명 41.9\%, 종합병원급 7 $\sim 15$ 명 44.3\%, 16명 이상 $53.6 \%$, 대학병원 41명 이상 $96.7 \%$ 로 병원급 이상이 되면서 급격히 증가하는 경향을 보였다 $(P$ $<0.01)$. 고용형태는 병원급은 전일제 근무 $92.5 \%$, 시간제 근무 $7.5 \%$, 종합병원은 전일제 근무 $91.8 \%$, 시간제 근무 $8.2 \%$, 대학 병원은 전일제 근무 $86.9 \%$, 시간제 근무 $13.1 \%$ 로 나타나 병원 급과 종합병원에서 비슷한 경향의 고용형태의 형태를 보였으 며, 대학병원에서는 시간제 근무 형태의 임시직 고용이 증가하 였다 $(P<0.05)$ (Table 3).

\section{4. 임상검사 건수}

Table 4는 병원 규모별에 따른 임상병리사의 수, 부서별 검사 건수, 1 인 검사건수, 1 인 적정 검사건수를 나타낸다.

임상화학부서의 임상병리사 인원은 의원급 1 6명 96.1\%, 병원급 1 6명 91.8\%, 종합병원급은 1 15명 97.4\%, 대학병 원은 1 15명 87.8\%, 16 40명 12.2\%로 나타났다. 1일 검사 건수는 의원급 100 건 미만 $76.3 \%, 100$ 600건 $21.0 \%$, 병원급
100 건 미만 $50.0 \%, 100$ 600건 40.5\%, 종합병원급은 100 건 미만 5.1\%, 100 600건 56.5\%, 600 1,000건 17.9\%, 1,000 3,000 건 $20.5 \%$, 대학병원은 100 건 미만 $9.1 \%, 100$ 600건 $9.1 \%, 600 \sim 1,000$ 건 $12.1 \%, 1,000 \sim 3,000$ 건 30.3\%, 3,000건 이상 $39.3 \%$ 로 나타났다. 임상병리사 1 인의 1 일 검사건수는 의 원급 100 건 미만 $84.2 \%, 100$ 600건 $13.2 \%$, 병원급 100 건 미 만 $74.3 \%, 100 \sim 600$ 건 $18.9 \%$, 종합병원급은 100 건 미만 $17.9 \%, 100$ 600건 $64.1 \%, 600 \sim 1,000$ 건 $17.9 \%$, 대학병원 은 100건 미만 9.1\%, 100 600건 39.4\%, 600 1,000건 $15.2 \%, 1,000 \sim 3,000$ 건 $6.1 \%, 3,000$ 건 이상 $30.3 \%$ 로 나타났 다. 임상병리사 1 인의 1 일 적정 검사건수는 의원급 100 건 미만 $84.3 \%, 100$ 600건 11.8\%, 병원급 100건 미만 $73.0 \%, 100$ 600건 18.9\%, 종합병원급은 100건 미만 30.8\%, 100 600건 $48.8 \%, 600 \sim 1,000$ 건 $20.4 \%$, 대학병원은 100 건 미만 $39.4 \%$, $100 \sim 600$ 건 39.4\%, 1,000 3,000건 21.2\%로 나타났다. 미생 물학부서의 임상병리사 인원은 의원급 1 6명 $100.0 \%$, 병원급 $1 \sim 6$ 명 $75.5 \%$, 종합병원급은 1 15명 80.0\%, 대학병원은 1

Table 1. General characteristics

\begin{tabular}{|c|c|c|}
\hline Characteristics & Categories & N (\%) \\
\hline \multirow[t]{2}{*}{ Gender } & Male & $122(27.7)$ \\
\hline & Female & $319(72.3)$ \\
\hline \multirow[t]{4}{*}{ Age } & $20 \mathrm{~s}$ & $124(28.1)$ \\
\hline & $30 \mathrm{~s}$ & $190(43.1)$ \\
\hline & $40 \mathrm{~s}$ & $115(26.1)$ \\
\hline & 50s over & $12(2.7)$ \\
\hline \multirow[t]{2}{*}{ Marital status } & Single & $203(46.0)$ \\
\hline & Married & $238(54.0)$ \\
\hline \multirow[t]{3}{*}{ Education } & College & $187(41.7)$ \\
\hline & University & $218(49.4)$ \\
\hline & $\begin{array}{l}\text { Master over } \\
\text { others }\end{array}$ & $\begin{array}{l}35(8.0) \\
4(0.9)\end{array}$ \\
\hline \multirow[t]{5}{*}{ Carrier } & $1 \sim 4$ yrs & $195(44.2)$ \\
\hline & $5 \sim 9$ & $104(23.6)$ \\
\hline & $10 \sim 19$ & $51(11.6)$ \\
\hline & $20 \sim 29$ & $87(19.7)$ \\
\hline & 30 over & $4(0.9)$ \\
\hline \multirow[t]{2}{*}{ Employment status } & Full-time & $388(88.0)$ \\
\hline & Part-time & $53(12.0)$ \\
\hline \multirow{4}{*}{$\begin{array}{l}\text { On-duty hours } \\
\text { (per weeks) }\end{array}$} & $40 \mathrm{hr}$ & $257(58.3)$ \\
\hline & $44 \mathrm{hrs}$ & $113(25.6)$ \\
\hline & 48 hrs over & $58(13.2)$ \\
\hline & Other & $13(2.9)$ \\
\hline \multirow{6}{*}{$\begin{array}{l}\text { Annual income } \\
\text { (million won) }\end{array}$} & Less than 2000 & $42(9.5)$ \\
\hline & $2000 \sim 3000$ & $183(41.5)$ \\
\hline & $3000 \sim 4000$ & $94(21.3)$ \\
\hline & $4000 \sim 5000$ & $40(9.1)$ \\
\hline & $5000 \sim 6000$ & $40(9.1)$ \\
\hline & 6000 over & $42(9.5)$ \\
\hline \multirow[t]{2}{*}{ Medical specialist } & Yes & $318(72.1)$ \\
\hline & No & $123(27.9)$ \\
\hline
\end{tabular}


96 Junghyun Kim, et al. Relationship between Number of Medical Technologist and Medical Test Count

Table 2. Satisfaction of medical technologist

\begin{tabular}{|c|c|c|c|}
\hline Characteristics & Categories & N (\%) & Mean (SE) \\
\hline Annual income (satisfaction) & & & $3.23(0.97)$ \\
\hline Working environment (satisfaction) & & & $3.12(0.91)$ \\
\hline Test accomplishment (satisfaction) & & & $3.21(0.84)$ \\
\hline \multirow[t]{5}{*}{ Welfare service (multi-choice) } & Retraining expenses & $284(64.4)$ & \\
\hline & Transportation expenses & $170(38.5)$ & \\
\hline & Educational expenses & $109(24.7)$ & \\
\hline & Food expenses & $87(19.7)$ & \\
\hline & Annual fee \& License benefit & $30(6.8)$ & \\
\hline
\end{tabular}

Table 3. Relationship between number of medical technologist and employment status according to hospital size

\begin{tabular}{|c|c|c|c|c|c|c|}
\hline \multirow{3}{*}{$\begin{array}{l}\text { Hospital size } \\
\text { Small }\end{array}$} & \multirow{3}{*}{$\begin{array}{c}\text { Number of hospital }{ }^{* *} \\
98(22.2)\end{array}$} & \multicolumn{3}{|c|}{ Number of $\mathrm{MT}^{\star \star}$} & \multirow{2}{*}{\multicolumn{2}{|c|}{ Employment status* }} \\
\hline & & \multicolumn{2}{|c|}{ N (\%) } & \multirow{2}{*}{$\frac{\text { Mean (SE) }}{5.8(0.54)}$} & & \\
\hline & & $1 \sim 6$ person & $66(67.3)$ & & full-time & $80(81.6)$ \\
\hline & & $7 \sim 15$ & $29(29.6)$ & & part-time & $18(18.4)$ \\
\hline & & $16 \sim 40$ & $3(3.1)$ & & & \\
\hline \multirow[t]{4}{*}{ Medium } & $93(21.1)$ & $1 \sim 6$ & $46(49.5)$ & $14.9(0.76)$ & full-time & $86(92.5)$ \\
\hline & & $7 \sim 15$ & $39(41.9)$ & & part-time & $7(7.5)$ \\
\hline & & $16 \sim 40$ & $4(4.3)$ & & & \\
\hline & & 41 over & $4(4.3)$ & & & \\
\hline \multirow[t]{4}{*}{ Large } & $97(22.0)$ & $1 \sim 6$ & $2(2.1)$ & $25.8(0.17)$ & full-time & 89 (91.8) \\
\hline & & $7 \sim 15$ & $43(44.3)$ & & part-time & $8(8.2)$ \\
\hline & & $16 \sim 40$ & $26(26.8)$ & & & \\
\hline & & 41 over & $26(26.8)$ & & & \\
\hline \multirow[t]{2}{*}{ Super } & $153(34.7)$ & $16 \sim 40$ & $5(3.3)$ & $45.4(1.24)$ & full-time & 133 (86.9) \\
\hline & & 41 over & $148(96.7)$ & & part-time & $20(13.1)$ \\
\hline Total & 441 & & & & & \\
\hline
\end{tabular}

${ }^{\star} P<0.05,{ }^{* *} P<0.01$

Abbreviation: MT, medical technologist.

15 명 $86.7 \%, 40$ 명이상 $13.3 \%$ 로 나타났다. 1 일 검사건수는 의 원급 100 건 미만 $100.0 \%$, 병원급 100 건 미만 $83.3 \%$, 종합병원 급은 100 건 미만 $60.0 \%, 100$ 300건 40.0\%, 대학병원은 100 건 미만 $13.3 \%, 100 \sim 300$ 건 $40.0 \%, 500$ 건 이상 $46.6 \%$ 로 나타 났다. 임상병리사 1 인의 1 일 검사건수는 의원급, 병원급, 종합 병원급에서 50건 미만 $100.0 \%$, 대학병원은 50건 미만 $73.4 \%$, 50 100건 13.4\%, 100 200건 13.3\%로 나타났다. 임상병리 사 1 인의 1 일 적정 검사건수는 의원급, 병원급, 종합병원급에서 50 건 미만 $100.0 \%$, 대학병원은 50건 미만 $86.7 \%, 50$ 100건 $13.3 \%$ 로 나타났다. 면역혈청학부서의 임상병리사 인원은 의원 급 1 6명 94.0\%, 병원급 1 6명 97.9\%, 종합병원급은 1 15 명 97.0\%, 대학병원은 1 15명 $72.7 \%, 16$ 40명 9.1\%, 40명 이상 $18.2 \%$ 로 나타났다. 1 일 검사건수는 의원급 100 건 미만 $78.0 \%, 100$ 600건 16.0\%, 병원급 100건 미만 75.9\%, 100 600 건 $18.9 \%$, 종합병원급은 100 건 미만 $33.3 \%, 100$ 600건 $51.5 \%, 600 \sim 1,000$ 건 $12.1 \%, 1,000 \sim 3,000$ 건 3.0\%, 대학병 원은 100 건 미만 $9.1 \%, 100 \sim 600$ 건 $18.2 \%, 600 \sim 1,000$ 건
$9.1 \%, 1,000 \sim 3,000$ 건 $36.3 \%, 3,000$ 건 이상 $27.3 \%$ 로 나타났 다. 임상병리사 1 인의 1 일 검사건수는 의원급 100 건 미만 $84.0 \%, 100$ 600건 10.0\%, 병원급 100건 미만 82.8\%, 100 600 건 $15.5 \%$, 종합병원급은 100 건 미만 $45.5 \%, 100$ 600건 $48.5 \%$, 대학병원은 100 건 미만 $9.1 \%, 100 ~ 600$ 건 $45.5 \%, 600$ 1,000 건 $18.2 \%, 1,000 \sim 2,000$ 건 27.3\%로 나타났다. 임상병리 사 1 인의 1 일 적정 검사건수는 의원급 100 건 미만 $82.0 \%, 100$ 600건 12.0\%, 병원급 100건 미만 81.0\%, 100 600건 $13.7 \%$, 종합병원급은 100 건 미만 $57.6 \%, 100$ 600건 39.4\%, 대학병원은 100 건 미만 63.6\%, 100 600건 36.4\%로 나타났 다. 혈액학부서의 임상병리사 인원은 의원급 1 6명 95.9\%, 병 원급 1 6명 89.9\%, 종합병원급은 1 15명 97.4\%, 대학병원 은 1 15명 90.0\%, 40명이상 $10.0 \%$ 로 나타났다. 1일 검사건수 는 의원급 100 건 미만 $77.0 \%, 100$ 600건 $17.6 \%$, 병원급 100 건 미만 $59.4 \%, 100 \sim 600$ 건 $27.5 \%$, 종합병원급은 100 건 미만 $5.3 \%, 100 \sim 600$ 건 52.6\%, 600 1,000건 13.2\%, 1,000 3,000 건 $28.9 \%$, 대학병원은 $600 \sim 1,000$ 건 $20.0 \%, 1,000$ 
Table 4. Relationship between number of medical technologist and number of medical test in field according to hospital size

\begin{tabular}{|c|c|c|c|c|c|c|c|}
\hline \multirow{2}{*}{ Fields } & & \multirow{2}{*}{ Category } & \multicolumn{4}{|c|}{ Hospital size } & \multirow{2}{*}{$P$-value } \\
\hline & & & Small & Medium & Large & Super & \\
\hline \multirow[t]{19}{*}{ Chemistry } & \multirow[t]{3}{*}{$A$} & $1 \sim 6$ person & $73(96.1)$ & $68(91.8)$ & $21(53.8)$ & $12(36.4)$ & \multirow[t]{3}{*}{$<0.001$} \\
\hline & & $7 \sim 15$ & $3(3.9)$ & $3(4.1)$ & $17(43.6)$ & $17(51.4)$ & \\
\hline & & $16 \sim 40$ & & $3(4.1)$ & $1(2.6)$ & $4(12.2)$ & \\
\hline & \multirow[t]{6}{*}{ B } & Less than 100 & $58(76.3)$ & $37(50.0)$ & $2(5.1)$ & $3(9.1)$ & \multirow[t]{6}{*}{$<0.001$} \\
\hline & & $100 \sim 600$ & $16(21.0)$ & $30(40.5)$ & $22(56.5)$ & $3(9.1)$ & \\
\hline & & $600 \sim 1,000$ & & $2(2.7)$ & 7 (17.9) & $4(12.1)$ & \\
\hline & & $1,000 \sim 3,000$ & $2(2.7)$ & $5(6.8)$ & $8(20.5)$ & $10(30.3)$ & \\
\hline & & $3,000 \sim 5,000$ & & & & $1(3.0)$ & \\
\hline & & 5,000 over & & & & $12(36.4)$ & \\
\hline & \multirow[t]{6}{*}{ C } & Less than 100 & $64(84.2)$ & $55(74.3)$ & $7(17.9)$ & $3(9.0)$ & \multirow[t]{6}{*}{$<0.001$} \\
\hline & & $100 \sim 600$ & $10(13.2)$ & $14(18.9)$ & $25(64.2)$ & $13(39.4)$ & \\
\hline & & $600 \sim 1,000$ & $2(2.6)$ & $5(6.8)$ & 7 (17.9) & $5(15.2)$ & \\
\hline & & $1,000 \sim 3,000$ & & & & $2(6.1)$ & \\
\hline & & $3,000 \sim 5,000$ & & & & $9(27.3)$ & \\
\hline & & 5,000 over & & & & $1(3.0)$ & \\
\hline & \multirow[t]{4}{*}{$\mathrm{D}$} & Less than 100 & 64 (84.3) & $54(73.0)$ & $12(30.8)$ & $13(39.4)$ & \multirow[t]{4}{*}{$<0.001$} \\
\hline & & $100 \sim 600$ & $9(11.8)$ & $14(18.9)$ & $19(48.8)$ & $13(39.4)$ & \\
\hline & & $600 \sim 1,000$ & $73(3.9)$ & $4(5.4)$ & $8(20.4)$ & & \\
\hline & & $1,000 \sim 3,000$ & & $2(2.7)$ & & $11(21.2)$ & \\
\hline \multirow[t]{13}{*}{ Microbiology } & \multirow[t]{4}{*}{$A$} & $1 \sim 6$ person & $10(100.0)$ & $9(75.0)$ & & $20(66.7)$ & \multirow[t]{4}{*}{$<0.001$} \\
\hline & & $7 \sim 15$ & & & $8(80.0)$ & $6(20.0)$ & \\
\hline & & $16 \sim 40$ & & $3(25.0)$ & $1(10.0)$ & & \\
\hline & & 41 over & & & $1(10.0)$ & $4(13.3)$ & \\
\hline & \multirow[t]{4}{*}{ B } & Less than 100 & $10(100.0)$ & $10(83.3)$ & $6(60.0)$ & $4(13.3)$ & $<0.001$ \\
\hline & & $100 \sim 300$ & & & $4(40.0)$ & $12(40.0)$ & \\
\hline & & $300 \sim 500$ & & $2(16.7)$ & & & \\
\hline & & 500 over & & & & $14(46.7)$ & \\
\hline & C & Less than 50 & $10(100.0)$ & $10(100.0)$ & $10(100.0)$ & $22(73.4)$ & $<0.001$ \\
\hline & & $50 \sim 100$ & & & & $4(13.3)$ & \\
\hline & & $100 \sim 200$ & & & & $4(13.3)$ & \\
\hline & D & Less than 50 & $10(100.0)$ & $10(100.0)$ & $10(100.0)$ & $26(86.7)$ & $<0.001$ \\
\hline & & $50 \sim 100$ & & $2(16.7)$ & & $4(13.3)$ & \\
\hline Immunology \& & $A$ & $1 \sim 6$ person & $47(94.0)$ & $51(97.9)$ & $17(51.5)$ & $1(9.1)$ & $<0.001$ \\
\hline Serology & & $7 \sim 15$ & $3(6.0)$ & $4(6.9)$ & $15(45.5)$ & 7 (63.6) & \\
\hline & & $16 \sim 40$ & & $3(5.2)$ & $1(3.0)$ & $1(9.1)$ & \\
\hline & & 41 over & & & & $2(18.2)$ & \\
\hline & $\mathrm{B}$ & Less than 100 & $39(78.0)$ & $44(75.9)$ & $11(33.3)$ & $1(9.1)$ & $<0.001$ \\
\hline & & $100 \sim 600$ & $8(16.0)$ & $11(18.9)$ & $17(51.6)$ & $2(18.2)$ & \\
\hline & & $600 \sim 1,000$ & & $2(3.5)$ & $4(12.1)$ & $1(9.1)$ & \\
\hline & & $1,000 \sim 3,000$ & $3(6.0)$ & $1(1.7)$ & $1(3.0)$ & $4(36.3)$ & \\
\hline & & $3,000 \sim 5,000$ & & & & $2(18.2)$ & \\
\hline & & 5,000 over & & & & $1(9.1)$ & \\
\hline & C & Less than 100 & $42(84.0)$ & $48(82.8)$ & $15(45.5)$ & $1(9.1)$ & $<0.001$ \\
\hline & & $100 \sim 600$ & $5(10.0)$ & $9(15.5)$ & $16(48.5)$ & $5(45.4)$ & \\
\hline & & $600 \sim 1,000$ & $2(4.0)$ & $1(1.7)$ & $2(6.0)$ & $2(18.2)$ & \\
\hline & & $1,000 \sim 2,000$ & $1(2.0)$ & & & $3(27.3)$ & \\
\hline & $\mathrm{D}$ & Less than 100 & $41(82.0)$ & $47(81.2)$ & 19 (57.6) & 7 (63.6) & $<0.001$ \\
\hline & & $100 \sim 600$ & $6(12.0)$ & $8(13.7)$ & $13(39.4)$ & $4(36.4)$ & \\
\hline & & $600 \sim 1,000$ & $2(4.0)$ & $1(1.7)$ & $1(3.0)$ & & \\
\hline & & $1,000 \sim 3,000$ & $1(2.0)$ & $2(3.4)$ & & & \\
\hline Hematology & $A$ & $1 \sim 6$ person & $71(95.9)$ & $62(89.9)$ & $18(47.4)$ & $2(10.0)$ & $<0.001$ \\
\hline & & $7 \sim 15$ & $3(4.1)$ & $4(5.8)$ & $19(50.0)$ & $16(80.0)$ & \\
\hline & & $16 \sim 40$ & & $3(4.3)$ & $1(2.6)$ & & \\
\hline & & 41 over & & & & $2(10.0)$ & \\
\hline
\end{tabular}


Table 4. Continued

\begin{tabular}{|c|c|c|c|c|c|c|c|}
\hline \multirow{2}{*}{ Fields } & & \multirow{2}{*}{ Category } & \multicolumn{4}{|c|}{ Hospital size } & \multirow{2}{*}{$P$-value } \\
\hline & & & Small & Medium & Large & Super & \\
\hline & \multirow[t]{6}{*}{ B } & Less than 100 & $57(77.0)$ & $41(59.5)$ & $2(5.3)$ & & $<0.001$ \\
\hline & & $100 \sim 600$ & $13(17.6)$ & $19(27.5)$ & $20(52.6)$ & $1(5.0)$ & \\
\hline & & $600 \sim 1,000$ & $1(1.4)$ & $3(4.3)$ & $5(13.2)$ & $4(20.0)$ & \\
\hline & & $1,000 \sim 3,000$ & $3(4.0)$ & $6(8.7)$ & $11(28.8)$ & $12(60.0)$ & \\
\hline & & $3,000 \sim 5,000$ & & & & $2(10.0)$ & \\
\hline & & $5,000 \sim 6,000$ & & & & $1(5.0)$ & \\
\hline & \multirow[t]{4}{*}{ C } & Less than 100 & $63(85.1)$ & $48(69.6)$ & $10(26.4)$ & & $<0.001$ \\
\hline & & $100 \sim 600$ & $8(10.9)$ & $15(21.7)$ & $17(44.7)$ & $10(50.0)$ & \\
\hline & & $600 \sim 1,000$ & $2(2.7)$ & $4(5.8)$ & $11(28.9)$ & $6(30.0)$ & \\
\hline & & $1,000 \sim 3,000$ & $1(1.3)$ & $2(2.9)$ & & $4(20.0)$ & \\
\hline & \multirow[t]{4}{*}{$\mathrm{D}$} & Less than 100 & $61(82.4)$ & $50(72.5)$ & $15(39.4)$ & $7(36.8)$ & $<0.001$ \\
\hline & & $100 \sim 600$ & $10(13.6)$ & $12(17.4)$ & $14(36.9)$ & $10(52.6)$ & \\
\hline & & $600 \sim 1,000$ & $2(2.7)$ & $5(7.2)$ & $8(21.1)$ & $1(5.3)$ & \\
\hline & & $1,000 \sim 3,000$ & $1(1.3)$ & $2(2.9)$ & $1(2.6)$ & $1(5.3)$ & \\
\hline \multirow[t]{11}{*}{ Blood bank } & \multirow[t]{4}{*}{ A } & $1 \sim 6$ person & $12(80.0)$ & $42(85.7)$ & $14(46.7)$ & $3(50.0)$ & $<0.001$ \\
\hline & & $7 \sim 15$ & $3(20.0)$ & $4(8.2)$ & $15(50.0)$ & $1(16.7)$ & \\
\hline & & $16 \sim 40$ & & $3(6.1)$ & $1(3.3)$ & & \\
\hline & & 41 over & & & & $2(33.3)$ & \\
\hline & \multirow[t]{3}{*}{$\mathrm{B}$} & Less than 100 & $15(100.0)$ & 46 (93.9) & $20(100.0)$ & $1(16.7)$ & $<0.001$ \\
\hline & & $100 \sim 300$ & & $3(6.1)$ & & $3(40.0)$ & \\
\hline & & $300 \sim 500$ & & & & $2(33.3)$ & \\
\hline & \multirow[t]{2}{*}{$C$} & Less than 50 & $15(100.0)$ & $46(93.9)$ & $30(100.0)$ & $6(100.0)$ & $<0.001$ \\
\hline & & $50 \sim 100$ & & $3(6.1)$ & & & \\
\hline & \multirow[t]{2}{*}{$\mathrm{D}$} & Less than 15 & $15(100.0)$ & $45(91.8)$ & $30(100.0)$ & $6(100.0)$ & $<0.001$ \\
\hline & & $50 \sim 100$ & & $4(8.2)$ & & & \\
\hline \multirow{16}{*}{$\begin{array}{l}\text { Urinalysis and } \\
\text { Body fluid }\end{array}$} & \multirow[t]{4}{*}{ A } & $1 \sim 6$ person & $22(88.0)$ & $14(77.8)$ & $1(9.1)$ & $1(12.5)$ & $<0.001$ \\
\hline & & $7 \sim 15$ & $3(12.0)$ & $1(5.6)$ & $9(81.8)$ & $5(62.5)$ & \\
\hline & & $16 \sim 40$ & & $3(16.6)$ & $1(9.1)$ & & \\
\hline & & 41 over & & & & $2(25.0)$ & \\
\hline & \multirow[t]{4}{*}{ B } & Less than 100 & $19(76.0)$ & $13(72.2)$ & $3(27.3)$ & $1(12.5)$ & $<0.001$ \\
\hline & & $100 \sim 600$ & $2(8.0)$ & $3(16.7)$ & $7(63.6)$ & $1(12.5)$ & \\
\hline & & $600 \sim 1,000$ & $2(8.0)$ & & $1(9.1)$ & $4(50.0)$ & \\
\hline & & $1,000 \sim 3,000$ & $2(8.0)$ & $2(11.1)$ & & $2(25.0)$ & \\
\hline & \multirow[t]{4}{*}{ C } & Less than 100 & $21(84.0)$ & $14(77.8)$ & $8(72.7)$ & $3(37.5)$ & $<0.001$ \\
\hline & & $100 \sim 600$ & $2(8.0)$ & $2(11.2)$ & $2(18.2)$ & $2(25.0)$ & \\
\hline & & $600 \sim 1,000$ & & $2(11.0)$ & $1(9.1)$ & $3(37.5)$ & \\
\hline & & $1,000 \sim 3,000$ & $2(8.0)$ & & & & \\
\hline & \multirow[t]{4}{*}{$\mathrm{D}$} & Less than 100 & $23(92.0)$ & $13(72.2)$ & $4(36.4)$ & $4(50.0)$ & $<0.001$ \\
\hline & & $100 \sim 600$ & $1(4.0)$ & $2(11.2)$ & 7 (63.6) & $4(50.0)$ & \\
\hline & & $600 \sim 1,000$ & & $1(5.6)$ & & & \\
\hline & & $1,000 \sim 3,000$ & $1(4.0)$ & $2(11.0)$ & & & \\
\hline \multirow[t]{11}{*}{ Molecular genetics } & $A$ & $1 \sim 6$ person & $6(85.7)$ & $1(25.0)$ & & $1(9.1)$ & 0.207 \\
\hline & & $7 \sim 15$ & $1(14.3)$ & & $4(80.0)$ & $8(72.7)$ & \\
\hline & & $16 \sim 40$ & & $3(75.0)$ & $1(20.0)$ & & \\
\hline & & 41 over & & & & $2(18.2)$ & \\
\hline & $\mathrm{B}$ & Less than 100 & $7(100.0)$ & $2(50.0)$ & $5(100.0)$ & $10(90.9)$ & $<0.001$ \\
\hline & & $100 \sim 300$ & & $2(50.0)$ & & & \\
\hline & & 300 over & & & & $1(9.1)$ & \\
\hline & C & Less than 50 & $7(100.0)$ & $2(50.0)$ & $5(100.0)$ & $11(100.0)$ & $<0.001$ \\
\hline & & $50 \sim 100$ & & $2(50.0)$ & & & \\
\hline & D & Less than 15 & $7(100.0)$ & $2(50.0)$ & $5(100.0)$ & $11(100.0)$ & $<0.001$ \\
\hline & & $50 \sim 100$ & & $2(50.0)$ & & & \\
\hline
\end{tabular}


Table 4. Continued

\begin{tabular}{|c|c|c|c|c|c|c|c|}
\hline \multirow{2}{*}{ Fields } & & \multirow{2}{*}{ Category } & \multicolumn{4}{|c|}{ Hospital size } & \multirow{2}{*}{$P$-value } \\
\hline & & & Small & Medium & Large & Super & \\
\hline \multirow[t]{16}{*}{ Blood collection } & \multirow[t]{4}{*}{ A } & $1 \sim 6$ person & $18(85.7)$ & $15(78.9)$ & $1(8.3)$ & $1(6.2)$ & \multirow[t]{4}{*}{$<0.001$} \\
\hline & & $7 \sim 15$ & $3(14.3)$ & $1(5.3)$ & $10(83.4)$ & $12(75.0)$ & \\
\hline & & $16 \sim 40$ & & $3(15.8)$ & 1 (8.3) & $1(6.2)$ & \\
\hline & & 41 over & & & & $2(12.6)$ & \\
\hline & \multirow[t]{6}{*}{$\mathrm{B}$} & Less than 90 & $20(95.2)$ & $13(68.4)$ & $1(8.3)$ & $5(31.3)$ & \multirow[t]{6}{*}{$<0.001$} \\
\hline & & $90 \sim 200$ & & $4(21.1)$ & $5(41.6)$ & $1(6.3)$ & \\
\hline & & $200 \sim 400$ & & & $5(41.8)$ & & \\
\hline & & $400 \sim 600$ & $1(4.8)$ & $2(10.5)$ & & $3(18.7)$ & \\
\hline & & $600 \sim 1,000$ & & & $1(8.3)$ & $2(12.5)$ & \\
\hline & & 1,000 over & & & & $5(31.2)$ & \\
\hline & \multirow[t]{3}{*}{$C$} & Less than 30 & $20(95.2)$ & 17 (89.5) & 10 (83.3) & $15(93.8)$ & \multirow[t]{3}{*}{$<0.001$} \\
\hline & & $30 \sim 60$ & $1(4.8)$ & & $2(16.7)$ & & \\
\hline & & $60 \sim 90$ & & $2(10.5)$ & & $1(6.2)$ & \\
\hline & \multirow[t]{3}{*}{$\mathrm{D}$} & Less than 30 & $21(100.0)$ & 17 (89.5) & $12(100.0)$ & $13(81.2)$ & \multirow[t]{3}{*}{$<0.001$} \\
\hline & & $30 \sim 60$ & & & & $3(18.8)$ & \\
\hline & & $60 \sim 90$ & & $2(10.5)$ & & & \\
\hline \multirow[t]{12}{*}{ Pathology } & \multirow[t]{4}{*}{ A } & $1 \sim 6$ person & 8 (88.9) & $10(66.7)$ & $5(23.8)$ & & \multirow[t]{4}{*}{$<0.001$} \\
\hline & & $7 \sim 15$ & $1(11.1)$ & $1(6.7)$ & $3(14.3)$ & & \\
\hline & & $16 \sim 40$ & & $4(26.6)$ & $13(61.9)$ & 14 (93.3) & \\
\hline & & 41 over & & & & $1(6.7)$ & \\
\hline & \multirow[t]{4}{*}{$\mathrm{B}$} & Less than 100 & $9(100.0)$ & $12(80.0)$ & $8(38.1)$ & $2(13.3)$ & 0.407 \\
\hline & & $100 \sim 500$ & & & $8(38.1)$ & $5(33.3)$ & \\
\hline & & $500 \sim 1,000$ & & 2 (13.3) & $1(4.8)$ & $6(40.1)$ & \\
\hline & & $1,000 \sim 3,000$ & & $1(6.7)$ & $4(19.0)$ & $2(13.3)$ & \\
\hline & C & Less than 50 & $9(100.0)$ & $12(80.0)$ & $20(95.2)$ & $8(73.3)$ & 0.203 \\
\hline & & $50 \sim 100$ & & $3(20.0)$ & $1(4.8)$ & $4(26.7)$ & \\
\hline & $\mathrm{D}$ & Less than 50 & $9(100.0)$ & $12(80.0)$ & $21(100.0)$ & $12(80.0)$ & 0.113 \\
\hline & & $50 \sim 100$ & & $3(20.0)$ & & $3(20.0)$ & \\
\hline Health checkup & $A$ & $1 \sim 6$ person & 66 (94.3) & $44(84.6)$ & $15(39.5)$ & & $<0.001$ \\
\hline & & $7 \sim 15$ & $4(5.7)$ & $4(7.7)$ & $18(47.4)$ & $3(100.0)$ & \\
\hline & & $16 \sim 40$ & & $4(7.7)$ & $5(13.1)$ & & \\
\hline & & 41 over & & & & & \\
\hline & $\mathrm{B}$ & Less than 100 & $55(78.6)$ & $39(75.0)$ & $12(31.6)$ & & $<0.001$ \\
\hline & & $100 \sim 600$ & $14(20.0)$ & $11(21.2)$ & $22(57.9)$ & $3(100.0)$ & \\
\hline & & $600 \sim 1,000$ & $1(1.4)$ & & $1(2.6)$ & & \\
\hline & & $1,000 \sim 2,000$ & & $2(3.8)$ & $3(7.9)$ & & \\
\hline & C & Less than 100 & $59(84.3)$ & $41(78.8)$ & $20(52.6)$ & & $<0.001$ \\
\hline & & $100 \sim 600$ & $11(15.7)$ & $9(17.4)$ & $15(39.5)$ & $3(100.0)$ & \\
\hline & & $600 \sim 1,000$ & & $2(3.8)$ & $3(7.9)$ & & \\
\hline & $\mathrm{D}$ & Less than 100 & $62(88.6)$ & $41(78.9)$ & $25(65.7)$ & $1(33.3)$ & $<0.001$ \\
\hline & & $100 \sim 600$ & $8(11.4)$ & $11(21.1)$ & $10(26.4)$ & $2(66.7)$ & \\
\hline & & $600 \sim 1,000$ & & & $3(7.9)$ & & \\
\hline Physiological & $A$ & $1 \sim 6$ person & $50(94.3)$ & $50(86.2)$ & $25(59.5)$ & $10(35.8)$ & $<0.001$ \\
\hline functions & & $7 \sim 15$ & $3(5.7)$ & $5(8.6)$ & $15(35.7)$ & $8(28.6)$ & \\
\hline & & $16 \sim 40$ & & $3(5.2)$ & $2(4.8)$ & $8(28.6)$ & \\
\hline & & 41 over & & & & & \\
\hline & $\mathrm{B}$ & Less than 10 & $47(88.7)$ & $47(81.1)$ & $23(54.8)$ & $22(78.6)$ & 0.202 \\
\hline & & $10 \sim 50$ & & $8(13.8)$ & $15(35.7)$ & $6(21.4)$ & \\
\hline & & $50 \sim 100$ & $4(7.5)$ & $1(1.7)$ & $3(7.1)$ & & \\
\hline & & $100 \sim 200$ & $2(3.8)$ & $2(3.4)$ & $1(2.4)$ & & \\
\hline & C & Less than 10 & $50(94.3)$ & $56(96.6)$ & 39 (92.9) & $27(95.4)$ & 0.214 \\
\hline & & $10 \sim 50$ & $3(5.7)$ & & $3(7.1)$ & $1(3.6)$ & \\
\hline & & $50 \sim 100$ & & $2(3.4)$ & & & \\
\hline & $\mathrm{D}$ & Less than 10 & $52(98.1)$ & 57 (98.3) & $42(100.0)$ & $27(96.4)$ & 0.204 \\
\hline & & $10 \sim 50$ & $1(1.9)$ & $1(1.7)$ & & $1(3.6)$ & \\
\hline
\end{tabular}

$P$-values were calculated by Student's $t$-test or Chi-square test.

Abbreviations: A, number of medical technologist in fields; B, number of medical test in fields; C, number of medical test per one medical technologist; D, number of optimal medical test per one medical technologist. 
3,000 건 $60.0 \%, 3,000$ 건 이상 $15.5 \%$ 로 나타났다. 임상병리사 1 인의 1 일 검사건수는 의원급 100 건 미만 $85.1 \%, 100$ 600건 $10.9 \%$, 병원급 100건 미만 69.6\%, 100 600건 21.7\%, 종합병 원급은 100 건 미만 $26.3 \%, 100 \sim 600$ 건 44.7\%, 600 1,000건 $28.9 \%$, 대학병원은 100 600건 50.0\%, 600 1,000건 30.0\%, $1,000 \sim 3,000$ 건 $20.0 \%$ 로 나타났다. 임상병리사 1 인의 1 일 적 정 검사건수는 의원급 100 건 미만 $82.4 \%, 100$ 600건 $13.6 \%$, 병원급 100 건 미만 $72.5 \%, 100$ 600건 17.4\%, 종합병원급은 100 건 미만 $39.5 \%, 100 \sim 600$ 건 $36.9 \%$, 대학병원은 100 건 미 만 $36.8 \%, 100 \sim 600$ 건 52.6\%, 600건 이상 $10.6 \%$ 로 나타났다. 혈액은행부서의 임상병리사 인원은 의원급 1 6명 $80.0 \%$, 병 원급 1 6명 85.7\%, 종합병원급은 1 15명 96.7\%, 대학병원 은 1 15명 66.7\%, 40명 이상 33.3\%로 나타났다. 1일 검사건 수는 의원급 100 건 미만 $100.0 \%$, 병원급 100 건 미만 $93.9 \%$, 종 합병원급은 100 건 미만 $100.0 \%$, 대학병원은 100 건미만 $16.7 \%, 100 \sim 300$ 건 40.0\%, 300 500건 33.3\%로 나타났다. 임상병리사 1 인의 1 일 검사건수는 의원급 100 건 미만 $100.0 \%$, 병원급 100건 미만 93.9\%, 종합병원급은 100건 미만 100.0\%, 대학병원은 100 건 미만 $100.0 \%$ 로 나타났다. 임상병리사 1 인 의 1 일 적정 검사건수는 의원급 100 건 미만 $100.0 \%$, 병원급 100 건 미만 $93.9 \%$, 종합병원급은 100 건 미만 $100.0 \%$, 대학병 원은 100 건 미만 $100.0 \%$ 로 나타났다. 요화학 및 체액검사부서 의 임상병리사 인원은 의원급 1 6명 88.8\%, 병원급 1 6명 $77.8 \%$, 종합병원급은 1 15명 90.9\%, 대학병원은 1 15명 $75.0 \%, 40$ 명이상 $25.0 \%$ 로 나타났다. 1 일 검사건수는 의원급 100 건 미만 $76.0 \%$, 병원급 100 건 미만 $72.2 \%$, 종합병원급은 100 건 미만 $27.3 \%, 100 \sim 600$ 건 63.6\%, 대학병원은 100건미 만 12.5\%, 100 600건 12.5\%, 600 1,000건 50.0\%, 1,000 $\sim 3,000$ 건 $25.0 \%$ 로 나타났다. 임상병리사 1 인의 1 일 검사건수 는 의원급 100 건 미만 $84.0 \%$, 병원급 100 건 미만 $77.8 \%$, 종합 병원급은 100 건 미만 $72.7 \%$, 대학병원은 100 건 미만 $37.5 \%$, $100 \sim 600$ 건 $25.5 \%, 600 \sim 1,000$ 건 37.5\%로 나타났다. 임상병 리사 1 인의 1 일 적정 검사건수는 의원급 100 건 미만 $92.0 \%$, 병 원급 100 건 미만 $72.2 \%$, 종합병원급은 100 건 미만 $36.4 \%, 100$ 600건 63.6\%, 대학병원은 100건 미만 50.0\%, 100 600건 $50.0 \%$ 로 나타났다. 분자유전학부서의 임상병리사 인원은 의원 급 1 6명 85.7\%, 병원급 1 6명 25.0\%, 종합병원급은 1 15 명 80.0\%, 대학병원은 1 15명 81.8\%, 40명이상 $18.2 \%$ 로 나 타났다. 1 일 검사건수는 의원급 100 건 미만 $100.0 \%$, 병원급 100 건 미만 $50.0 \%$, 종합병원급은 100 건 미만 $100.0 \%$, 대학병 원은 100 건 미만 $90.9 \%, 300$ 건 이상 $9.1 \%$ 로 나타났다. 임상병
리사 1 인의 1 일 검사건수와 적정 검사건수는 의원급, 종합병원 급, 대학병원은 50건 미만 $100.0 \%$ 로 나타났다. 외래채혈실의 임상병리사 인원은 의원급 1 6명 85.7\%, 7 15명 14.3\%, 병 원급 1 15명 84.2\%, 종합병원급은 1 15명 91.7\%, 대학병원 은 1 15명 81.2\%, 16 40명 6.2\%, 40명이상 $12.6 \%$ 로 나타났 다. 1 일 채혈건수는 의원급 90 건 미만 $95.2 \%$, 병원급 200 건 미 만 89.7\%, 종합병원급은 200건 미만 49.9\%, 200 400건 $41.7 \%$, 대학병원은 400 건 미만 $37.4 \%, 400 ~ 1,000$ 건 $31.2 \%$, 1,000 건 이상 $31.2 \%$ 로 나타났다. 임상병리사 1 인의 1 일 검사 건수는 의원급 30 건 미만 $95.2 \%$, 병원급 30 건 미만 $89.5 \%$, 종 합병원급은 30건 미만 $83.3 \%$, 대학병원은 60건 미만 $93.8 \%$, 60 건 이상 $6.2 \%$ 로 나타났다. 임상병리사 1 인의 1 일 적정 검사 건수는 의원급 30 건 미만 $100.0 \%$, 병원급 30 건 미만 $89.5 \%$, 종 합병원급은 30 건 미만 $100.0 \%$, 대학병원은 30건 미만 $81.2 \%$, $30 \sim 60$ 건 18.8\%로 나타났다. 건강검진부서의 임상병리사 인 원은 의원급 1 6명 94.3\%, 병원급 1 6명 84.6\%, 종합병원급 은 1 6명 39.5\%, 7 15명 47.4\%, 대학병원은 7 15명 $100.0 \%$ 나타났다. 1 일 검사건수는 의원급 100 건 미만 $78.6 \%$, 병원급 100 건 미만 $75.0 \%$, 종합병원급은 100 건 미만 $31.6 \%$, 100 600건 미만 57.9\%, 대학병원은 100 600건 100.0\%로 나타났다. 임상병리사 1 인의 1 일 검사건수는 의원급 100 건 미 만 $84.3 \%$, 병원급 100 건 미만 $78.8 \%$, 종합병원급은 100 건 미 만 52.6\%, 100 600건 미만 39.5\%, 대학병원은 100 600건 $100.0 \%$ 로 나타났다. 임상병리사 1인의 1일 적정 검사건수는 의원급 100 건 미만 $88.6 \%$, 병원급 100 건 미만 $78.8 \%$, 종합병 원급은 100 건 미만 $65.8 \%, 100 ~ 600$ 건 미만 $26.4 \%$, 대학병원 은 100 건 미만 $33.3 \%, 100 \sim 600$ 건 66.7\%로 나타났다. 병리과 의 임상병리사 인원은 의원급 1 6명 88.9\%, 병원급 1 15명 $73.4 \%$, 종합병원급은 1 15명 38.1\%, 16 40명 61.9\%, 대학 병원은 16 40명 93.3\%, 40명이상 6.7\%로 나타났다. 1 일 검사 건수는 병원급 100 건 미만 $80.1 \%$, 종합병원급은 500건 미만 $76.2 \%$, 대학병원은 500건 미만 46.6\%, 500 1,000건 40.0\%, 1,000 건 이상 $13.3 \%$ 로 나타났다. 임상병리사 1 인의 1 일 검사 건수는 병원급 50건 미만 $80.0 \%$, 종합병원급은 50건 미만 $95.2 \%$, 대학병원은 50건 미만 $73.3 \%, 50$ 100건 26.7\%로 나 타났다. 임상병리사 1 인의 1 일 적정 검사건수는 병원급 50 건 미 만 $80.0 \%$, 종합병원급은 50건 미만 $100.0 \%$, 대학병원은 50건 미만 80.0\%, 50 100건 20.0\%로 나타났다. 병원규모별 임상 병리사의 인원과의 관련성이 통계적으로 유의함을 나타내었다 $(P<0.001)$. 생리기능검사부서의 임상병리사 인원은 의원급 1 6명 94.3\%, 병원급 1 6명 86.2\%, 종합병원급은 1 15명 
$95.2 \%$, 대학병원은 1 15명 $64.4 \%, 16$ 40명 $28.6 \%$ 로 나타 났다. 1 일 검사건수는 의원급 10 건 미만 $88.7 \%$, 병원급 10 건 미 만 81.0\%, 종합병원급은 10건 미만 54.8\%, 10 50건35.7\%, 대학병원은 10 건 미만 $78.6 \%, 10 \sim 50$ 건 $21.4 \%$ 로 나타났으나 통계적으로 유의하지 않았다 $(P=0.202)$. 임상병리사 1 인의 1 일 검사건수는 의원급 10 건 미만 $94.3 \%$, 병원급 10 건 미만 $96.6 \%$, 종합병원급은 10 건 미만 $92.9 \%$, 대학병원은 10 건 미만 $95.4 \%$ 로 나타났으나 통계적으로 유의하지 않았다 $(P=0.214)$. 임상병 리사 1 인의 1 일 적정 검사건수는 의원급 10 건 미만 $98.1 \%$, 병원 급 10 건 미만 $98.3 \%$, 종합병원급은 10 건 미만 $100.0 \%$, 대학병 원은 10 건 미만 $96.4 \%$ 로 나타났으나 통계적으로 유의하지 않 았다 $(P=0.204)$. 병원규모별 임상병리사의 인원과의 관련성에 서 통계적으로 유의함을 나타내었다 $(P<0.001)$. 병상수에 따른 진단검사의학과 분류시 병원의 특성에 의한 검사건수의 차이가 커 진단검사의학과에 대한 비교로는 적절하지 않았다. 부서별 검사건수는 진단검사의학과의 규모가 커짐에 따라 증가함을 보 였다. 그러나 임상병리사 1 인의 1 일 검사건수는 의원급과 병원 급이 거의 비슷하였으며, 종합병원과 대학병원의 차이가 나타 났다. 임상병리사 1 인의 1 일 적정 검사건수는 1 인 1 일 검사검수 와 큰 차이가 보이지 않았다(Table 4).

\section{5. 정도관리}

Table 5는 복수응답으로 병원규모별, 부서별 정도관리 시간 을 나타낸다. 병원규모별 정도관리시간은 1 시간 미만이 의원급 $95.9 \%$, 병원급 $96.8 \%$, 종합병원급 $98.0 \%$, 대학병원은 1 시간미 만 $75.2 \%, 1$ 2시간 $9.8 \%, 2$ 시간이상 $15.0 \%$ 로 대학병원급으 로 갈수록 정도관리시간은 증가하는 것으로 나타났다 $(P<0.001)$. 임상화학부서의 정도관리는 의원급 1 시간미만 $100.0 \%$, 병원 급 1시간미만 $95.7 \%, 1$ 2시간 $4.3 \%$, 종합병원급은 1시간미만 $91.8 \%, 1 \sim 2$ 시간 $8.2 \%$, 대학병원 1시간미만 $75.4 \%, 1$ 2시간 $24.6 \%$ 로 나타났다 $(P<0.001)$. 미생물학부서의 정도관리는 종 합병원급은 1 시간미만 $77.8 \%, 1$ 2시간 $22.2 \%$, 대학병원 1 시 간미만 $82.5 \%, 1 \sim 2$ 시간 $17.5 \%$ 로 나타났다 $(P<0.001)$. 면역 혈청학부서의 정도관리는 의원급 1 시간미만 $100.0 \%$, 병원급 1 시간미만 94.0\%, 1 2시간 6.0\%, 종합병원급은 1시간미만 $94.9 \%, 1$ 2시간 $5.1 \%$, 대학병원 1시간미만 $80.0 \%, 1$ 2시간 $20.0 \%$ 로 나타났다 $(P<0.001)$. 혈액학부서의 정도관리는 의원 급 1시간미만 $100.0 \%$, 병원급 1시간미만 95.5\%, 1 2시간 $4.5 \%$, 종합병원급은 1시간미만 $91.1 \%, 1$ 2시간 $8.9 \%$, 대학병 원 1시간미만 76.3\%, 1 2시간 23.7\%로 나타났다 $(P<0.001)$.

Table 5. Quality control

\begin{tabular}{|c|c|c|c|c|c|c|}
\hline \multirow{2}{*}{ Field } & \multirow{2}{*}{ QC Category } & \multicolumn{4}{|c|}{ Hospital size $e^{\star \star}$} & \multirow{2}{*}{$P$-value } \\
\hline & & Small & Medium & Large & Super & \\
\hline Chemistry & $\begin{array}{l}\text { Less than } 1 \text { hrs } \\
1 \sim 2\end{array}$ & $78(100.0)$ & $\begin{aligned} 66 & (95.7) \\
3 & (4.3)\end{aligned}$ & $\begin{aligned} 45 & (91.8) \\
4 & (8.2)\end{aligned}$ & $\begin{array}{l}49(75.4) \\
16(24.6)\end{array}$ & $<0.001$ \\
\hline Microbiology & $\begin{array}{l}\text { Less than } 1 \text { hrs } \\
1 \sim 2\end{array}$ & & & $\begin{array}{l}7(77.8) \\
2(22.2)\end{array}$ & $\begin{array}{ll}52 & (82.5) \\
11 & (17.5)\end{array}$ & $<0.001$ \\
\hline Immunology \& Serology & $\begin{array}{l}\text { Less than } 1 \text { hrs } \\
1 \sim 2\end{array}$ & $37(100.0)$ & $\begin{aligned} 47 & (94.0) \\
3 & (6.0)\end{aligned}$ & $\begin{aligned} 37 & (94.9) \\
2 & (5.1)\end{aligned}$ & $\begin{array}{l}44(80.0) \\
11(20.0)\end{array}$ & $<0.001$ \\
\hline Hematology & $\begin{array}{l}\text { Less than } 1 \text { hrs } \\
1 \sim 2\end{array}$ & $74(100.0)$ & $\begin{array}{c}63(95.5) \\
3(4.5)\end{array}$ & $\begin{aligned} 41 & (91.1) \\
4 & (8.9)\end{aligned}$ & $\begin{array}{l}45(76.3) \\
14(23.7)\end{array}$ & $<0.001$ \\
\hline Blood bank & $\begin{array}{l}\text { Less than } 1 \text { hrs } \\
1 \sim 2 \text { hrs }\end{array}$ & $2(100.0)$ & $34(100.0)$ & $\begin{array}{l}33(89.2) \\
4(10.8)\end{array}$ & $\begin{array}{ll}38 & (77.6) \\
11 & (22.4)\end{array}$ & $<0.001$ \\
\hline Urinalysis \& Body fluid & $\begin{array}{l}\text { Less than } 1 \text { hrs } \\
1 \sim 2\end{array}$ & $10(100.0)$ & $\begin{array}{l}6(66.7) \\
3(33.3)\end{array}$ & $\begin{array}{c}18(81.8) \\
4(18.2)\end{array}$ & $\begin{array}{l}41(75.9) \\
13(24.1)\end{array}$ & $<0.001$ \\
\hline Molecular genetics & $\begin{array}{l}\text { Less than } 1 \text { hrs } \\
1 \sim 2\end{array}$ & & & $\begin{array}{l}5(83.3) \\
1(16.7)\end{array}$ & $\begin{array}{c}25(73.5) \\
9(26.5)\end{array}$ & $<0.001$ \\
\hline Blood collection & Less than 1 hrs & $5(100.0)$ & $3(100.0)$ & $4(100.0)$ & $20(100.0)$ & $<0.001$ \\
\hline Pathology & Less than $1 \mathrm{hrs}$ & $3(100.0)$ & $7(100.0)$ & $20(100.0)$ & $18(100.0)$ & $<0.001$ \\
\hline Health checkup & Less than $1 \mathrm{hrs}$ & $53(100.0)$ & $40(100.0)$ & $28(100.0)$ & $7(100.0)$ & $<0.001$ \\
\hline Physiological functions & Less than $1 \mathrm{hrs}$ & $44(100.0)$ & $50(100.0)$ & $34(100.0)$ & $30(100.0)$ & $<0.001$ \\
\hline Total & $\begin{array}{l}\text { Less than } 1 \text { hrs } \\
1 \sim 2 \\
2 \text { hrs over }\end{array}$ & $\begin{array}{c}94(95.9) \\
4(4.1) \\
0(0)\end{array}$ & $\begin{array}{c}90(96.8) \\
3(3.2) \\
0(0)\end{array}$ & $\begin{aligned} 95 & (98.0) \\
1 & (1.0) \\
1 & (1.0)\end{aligned}$ & $\begin{aligned} 115 & (75.2) \\
15 & (9.8) \\
23 & (15.0)\end{aligned}$ & $<0.001$ \\
\hline
\end{tabular}

** $p<0.01$.

$P$-values were calculated by Student's $t$-test or Chi-square test. Abbreviation: MT, medical technologist. 
혈액은행부서의 정도관리는 의원급 및 병원급 1 시간미만 $100.0 \%$, 종합병원급은 1시간미만 $89.2 \%, 1$ 2시간 $10.8 \%$, 대 학병원 1시간미만 $77.6 \%, 1 \sim 2$ 시간 $22.4 \%$ 로 나타났다 $(P$ $<0.001)$. 요화학 및 체액검사부서의 정도관리는 의원급 1 시간 미만 $100.0 \%$, 병원급 1 시간미만 $66.7 \%, 1$ 2시간 $33.3 \%$, 종합 병원급은 1시간미만 $81.8 \%, 1$ 2시간 $18.2 \%$, 대학병원 1시간 미만 75.9\%, 1 2시간 $24.1 \%$ 로 나타났다 $(P<0.001)$. 분자유 전학부서의 정도관리는 종합병원급은 1 시간미만 $83.3 \%, 1$ 2 시간 $16.7 \%$, 대학병원 1 시간미만 $73.5 \%, 1 \sim 2$ 시간 $26.5 \%$ 로 나 타났다 $(P<0.001)$. 외래채혈실, 건강검진, 병리과, 생리기능검 사부서의 정도관리는 의원급, 병원급, 종합병원급, 대학병원 1 시간미만이 $100.0 \%$ 로 나타났다 $(P<0.001)$ (Table 5).

\section{고 찰}

최근 우리나라는 경제성장과 더불어 국민소득, 교육수준 그 리고 생활수준이 향상됨에 따라 국민의 건강에 대한 관심이 고 조되고 있으며, 나아가 평균수명의 연장으로 인한 노령인구의 증가 그리고 전 국민 의료보험실시 등으로 의료수요가 계속 증 가하고 있다[1]. 이에 따라 날로 증가하는 보건의료수요에 대응 하는 적정 서비스 공급과 이를 위한 의료 인력의 확충은 국민복 지 차원에서 필수 불가결한 요소이다[19-22]. 진단검사의학과 의 적정한 인력규모의 활용은 대단히 중요하다. 검사인력의 과 잉은 병원 및 기관의 경영악화를 가져올수 있지만 반대로 열악 한 인력 운용은 모든 검사의 질 저하를 반드시 수반할 수밖에 없 기 때문이다. 이를 판단하는 기준을 적립하는 일은 매우 복잡하 고 아직 표준화된 지침은 없다. 정확하게 진단검사의학과를 판 단하고 그 인력의 적정성을 판별하려면 검사실의 규모 및 업무 의 복잡성을 고려해야 한다[23-25]. 본 연구는 진단검사의학의 시설 및 제반 사항과 검사인력의 개인정보에 대한 설문을 이용 하여 진단검사의학과의 효율성에 대한 기초자료로서 활용하고 자 시행하였다. 자료의 구성이 대한민국 진단검사의학과의 대 표성을 지니고 있다고 볼 수는 없으나 대학병원 및 종합병원의 비율이 상대적으로 많아 본 연구에서 추구하는 검사의 난이도 나 직원의 경력 등을 판단하는 데에는 도움이 되었다고 생각한 다. 진단검사의학과의 임상병리사수에 따라 분류 부서별 1 일 검 사건수와 임상병리사 1 인 1일 검사건수 등을 비교한 결과 부서 별 1 일 검사건수 검사건수는 병상수에 따른 분류와 비슷한 상관 관계를 보였다. 또한 임상병리사 1 인당 1 일 검사건수는 의원, 병원, 종합병원, 대학병원 진단검사의학과간의 간의 유의한 차 이가 있었다. 이는 상급병원으로 갈수록 진단검사의학과의 검
사장비의 자동화 및 전산화의 영향으로 생각된다. 임상병리과 전문의 상주여부는 100 병상 이하 규모의 병원진단검사의학과 에서는 없었으나종합병원의 진단검사의학과에서는 $68 \%$, 대학 병원이상의 진단검사의학과는 $100 \%$ 근무하고 있었다. 임상병 리사는 의원급은 평균 5.8 명 정도로 각 검사분야당 1 명 정도의 임상병리사가 근무하고 있으나, 병원급 14.9 명, 종합병원 25.8 명, 대학병원진단검사의학과에서는 평균 45.4 명으로 급격한 증가를 보였고 진단검사의학과의 규모가 커짐에 따라 계약직 고용이 증가하여 종합병원이상의 진단검사의학과에서는 계약 직이 20 35\%의 분포를 보였다. 특히 계약직 비중이 가장 큰 부 서는 외래채혈실로 빅5의 주요병원은 유아채혈실을 따로 운영 하고 있으며 1일 외래 채혈환자수는 2,000 3,500명, 직원수 는 18 37명 수준으로 정규직 대 비정규직비율이 대부분 50\% 이상으로 비정규직 비율이 매우 높은 수준이었다. 이는 비용측 면에서의 절감효과와 인력의 유연성에 장점이 있으나 업무의 숙련도와 책임감에서 떨어지는 단점이 있다. 또한 임상병리상 의 1 일 검사건수와 1 일 적정검사건수의 차이는 상급병원으로 갈수록 감소하는 것으로 나타났다. 이는 정도관리여부에 따른 업무량의 차이에 기인할 수 있음을 시사한다 할 수 있다. 즉 상급 병원의 부서별 정도관리 평균 시간은 2 시간 이내로 나타났고, 상급병원으로 갈수록 정도관리에 할애 하는 시간이 많아 1 일 검 사건수와 1 일 적정 검사건수의 차이는 감소하였다. 의원급 및 병원급에서의 정도관리를 하지 않는 곳도 존재하는 바 이는 의 원급에서는 최소한의 임상병리사로 진단검사의학과전반의 업 무를 처리해야 하므로 인원배치측면에서의 근무 유연성이 상급 병원보다 부족한 것으로 생각할 수 있다. 또한 급여만족도, 근무 환경만족도, 검사성취도, 복지제도측면에서 대부분 보통수준 이었으며 의원급, 병원급에서의 불만족도 다수 차지하는 것으 로 나타났다. 이는 선진국형 의료 수준에 맞는 신뢰성 있는 검사 의 데이터를 제공하기 위해 임상병리사의 근무환경은 매우 중 요한 사인이 아닐 수 없음을 시사한다 할 수 있다. 임상병리사의 업무의 수요에 비해 임상병리사의 수요가 부족하고 종사자들에 대한 처우 수준이 낮아 결과적으로 의료서비스 질 제고에 부정 적 영향을 미칠 것이라는 지적을 받아 왔다. 따라서 국민 건강권 확보 측면에서 일자리의 양을 늘리고 신속 정확한 신뢰성 있는 데이터를 제공해야 한다. 임상병리사의 근무환경에 따른 근무 의 만족도와 임상검사의 정확도를 높이기 위해서라도 임상병리 사의 처우개선에 초점을 맞추어야 할 것이다. 본 연구의 결과가 학계나 관련 의료계 나아가 국가의 임상병리사 관련 진단검사 의학과 인력수급 및 진단검사의학과 운영 정책 및 계획수립에 조금이나마 도움을 주는 기초자료로서 유용하게 이용될 것으로 
사료된다. 또한 보건의료전달체계를 합리화하여 $1,2,3$ 차 기관 별로 임상병리사 인력을 적정하게 배분한다면 보건의료공급의 효율성이 높아져서 증대하는 보건의료수요에 적절하게 대처할 수 있을 것이다. 본 연구의 제한점은 의료기관의 규모, 의료자동 화의 진전에 따라 결과의 변화폭이 커질 수 있다는 점 등이 본 연 구의 결과를 해석할 때 고려되어야 할 것이다. 이러한 점들은 현 재에는 자료 등의 미비로 고찰되기 힘들지만 향후의 연구과제 로 남아있다고 할 수 있다. 또한 생리기능검사는 검사항목의 종 류에 따라 소요시간이 상이 한 점이 반영되지 못한 한계점이 있 다. 추후 후속연구를 통해 검사항목별 추가 분석이 보완적으로 이루어져야 할 것으로 생각된다.

\section{요 약}

본 연구는 국내의 진단검사의학과의 검사현황 및 인력배치 현황과 검사 건수를 파악하기 위함이다. 지역별, 규모별 임상병 리사를 대상으로 설문조사를 실시하여 최종 441 부를 분석 자료 로 사용하였다. 자료의 분석은 STATA (version 12.0)를 이용하 여 Descriptive statistics analysis, Chi-square test, ANOVA test를 실시하였다. 병원 규모별 임상병리사 분포는 의원급 5.8 명, 병원급 14.9 명, 종합병원 25.8 명, 대학병원 45.4 명으로 나 타났다. 부서별검사건수, 1 인 1일 검사건수는 의원, 병원, 종합 병원, 대학병원간의 유의한 차이가 있었다. 임상병리사의 1 일 검사건수와 1 일 적정 검사건수의 차이는 상급병원으로 갈수록 감소하는 것으로 나타났다. 정도관리는 상급병원의 부서별 정 도관리 평균 시간은 2 시간 이내로 나타났다. 급여만족도, 근무 환경만족도, 검사성취도, 복지제도측면에서 의원, 병원급에서 불만족도 다수 차지하는 것으로 나타났다. 이는 선진국형 의료 수준에 맞는 신뢰성 있는 검사의 데이터를 제공하기 위해 임상 병리사의 근무환경에 따른 근무의 만족도와 임상검사의 정확도 를 높이기 위해서라도 임상병리사의 처우개선에 초점을 맞추어 야 할 것으로 사료된다.

Acknowledgements: This work was supported by the Korean Association Medical Technologist research fund (2017).

\section{Conflict of interest: None}

Author's information (Position): Kim J ${ }^{1}$, Professor; Kim $\mathrm{DE}^{1}$, Professor; Yoon JS ${ }^{2}$, Professor; Lee JS $S^{3}$, M.T.; Park $\mathrm{TW}^{4}$, M.T.

\section{REFERENCES}

1. Greenberg L, Cultice JM. Forecasting the need for physicians in the United States: The health resources and services administration's physician requirements model. Health Serv Res. 1997;31:723-737.

2. Kim IS, Kim SY. Converged relationship between oral health education and dental health behavior of high school students. JCIT. 2016;6:107-114.

3. Kim SY. Convergence Study on The influence of dental hygiene students' Stress in their major satisfaction and career-decision attitude. JCIT. 2016;6:115-122.

4. Park SY. Issues and challenges of nursing workforce supply to improve the quality of health care services. $\mathrm{KJCH}$. 2018;6:21-25.

5. Kim SY, Kim SJ, Shin YI. Models of rehabilitation medical service delivery system in the world. J Korean Med Assoc. 2017;60:875-884. https://doi.org/10.5124/jkma.2017.60.11.875.

6. Oh YH. The 2006 Survey on national health care resources: results and policy implications. Heath and Social Welfare Forum. 2007;11:88-102.

7. Jung YH, Ko SJ. Policy for medical workforce planning: lessons from the experiences of Australia and U.K. Heath and Social Welfare Forum. 2005;6:98-109.

8. Park SH, Lee KS. Changes in the occupational structure and the spatial characteristics of employment distribution in Korea. Journal of the Korean Geographical Society. 2016;51:401-420.

9. Ha YJ. A Convergence study on the effects of satisfaction of nurses using the electronic medical record system on job stress. Journal of the Korea Convergence Society. 2017;8:69-78.

10. Heffler S, Smith S, Keehan S. Clemens MK, Won G, Zezza M. Health spending projections for 2002-2012. Health Aff (Millwood). 2003;3:54-65. https://doi.org/10.1377/hlthaff.W3.54.

11. Valdez AP. Competencies of career-entry medical technology graduates of Lyceum of Batangas: Basis for enhancement of the internship training program. JPAIR Multidisciplinary Journal. 2010;4:16-33. http://doi.org/10.7719/jpair.v4i1.98.

12. Harmening DM, Castleberry BM. Defining the roles of medical technologists and medical laboratory technicians. Lab Med. 1996;26:175-178. https://doi.org/10.1093/labmed/26.3.175.

13. Kim DH. Study on the supply and demand for the physician manpower in Korea. Health and Social Science. 2000; 6.7:221-239.

14. Jung MY, Cha YJ. An analysis on the status and supply-demand of occupational therapists in Korea. KSOT. 2009;17:113-127.

15. Choi KH, Cho JK. Analysis on Working Force Supply of Radiologic Technologist in Korea. Journal of Digital Convergence. 2017;15:489-495.

16. Park GS. The analysis of the current state of behavior therapy related professional training programs, placement and service offerings. JEBD. 2014;30:1-27.

17. Jun EK. Nursing time use in a Newborn Intensive Care Unit (NICU). JKANA. 2000;6:55-81.

18. Lee CH, You SW, Lee JD. Reaserch on working environment of medical technologists in the Electrophysiologic laboratory. Korean J Clin Lab Sci. 2002;34:210-219. 
19. Van GM, Batenburg R, Van der, Velden Lud LF. Ten years of health workforce planning in the Netherland: a tentative evaluation of GP planning as an example. Hum Resour Health. 2012;10:21.

20. Van GM, Batenburg R, Van der, Velden Lud LF. The accuracy of general practitioner workforce projections. Hum Resour Health. 2013;11:31.

21. Batenburg R. Health workforce planning as a balancing act-the Dutch case. EHMA Health Workforce Meeting; 2012 November 28; Budapest, Hungary.

22. Aki EA, Mustafa R, Bdair F, Schünemann HJ. The United States physician workforce and international medical graduates: trends and characterisics. J Gen Intern Med. 2007;22:264-268.

23. Wood J. The role, duties and responsibilities of technologists in the clinical laboratory. Clin Chim Acta. 2002;319:127-132.

24. Ward-Cook K, Tatum DS, Jones G. Medical technologist core job tasks still reign. Lab Medicine. 2000;31:375-379. https://doi.org/10.1309/3L3E-8CNP-RQL8-H154.

25. Blau G, Surges Tatum D, Ward-Cook K, Guiles HJ. Correlates of fundamental skills versus complex skills for medical technologists. J Allied Health. 2003;32:3-9. 